\title{
MATERIAL PROPERTIES AFFECTING THE MACHINABILITY OF INCONEL 718
}

\author{
Maria Krook $^{1}$, Viktor Recina ${ }^{2}$, Birger Karlsson ${ }^{1}$ \\ ${ }^{1}$ Department of Materials and Manufacturing Technology, Chalmers University of Technology, \\ SE-412 96 Göteborg, Sweden \\ ${ }^{2}$ Volvo Aero Corporation, SE-461 81 Trollhättan, Sweden
}

Keywords: Machinability, Cemented carbide tool, Carbides, Microstructure

\begin{abstract}
The machinability of Inconel 718 was studied. In part I, wear on cemented carbide tool inserts from turning operations on low pressure turbine cases were measured and correlated to material properties like chemical composition, microstructure and strength. This study showed that carbide forming elements like titanium and niobium are affecting the machinability negatively. Carbides are hard and abrasive particles that wear down the tool inserts. It was also concluded that strength are of minor importance to machinability on fully heat treated Inconel 718 in the range tested. In part II, the influence of microstructure on machinability was studied on designed work material. It was concluded that grain size has a large impact on machinability due to deformation hardening. It was also seen that the role of $\delta$-phase seems to be of minor importance for the machinability.
\end{abstract}

\section{Introduction}

Machining of nickel based superalloys to complicated parts is often a challenging issue associated with large costs. Variations in materials microstructures caused by differences in chemical composition, casting and forging techniques as well as heat treatments may lead to variations in machinability. A technically important example is manufacturing of turbine cases for jet engines. The present study deals with the machining behaviour during manufacturing of low pressure turbine cases for large commercial engines. These cases represent an important business area at Volvo Aero Corporation, presently contributing with about $70 \%$ of the whole world production.

The present systematic investigation was undertaken to study the influence of material variations on the machinability of Inconel 718. In part I, the study was performed on production parts in a work shop environment. The tool wear on cemented carbide tools were measured and correlated to material properties such as microstructure, chemical composition and strength. In part II, machinability experiments on designed work material were performed outside the production environment. In this case it was possible to obtain larger variations in microstructure than what is normally reached under regular production conditions.

\section{Experimental}

$\underline{\text { Materials - study I }}$

The low pressure turbine case used in the study was manufactured from a ring-rolled forging of the nickel based superalloy Inconel 718. The ingot used by the forger was double melted through 
a Vacuum Induction Melting (VIM) and Vacuum Arc Remelting (VAR) practice. The ingot was converted to a 305 or $355 \mathrm{~mm}$ billet, which was upset followed by a backward extrusion operation to create a donut-shaped forging. After increasing the diameter of the donut through saddling the forging was shaped through a number of ring rolling and forging steps operated at temperatures ranging from $990{ }^{\circ} \mathrm{C}$ to $1100{ }^{\circ} \mathrm{C}$. After forging to a typical cross section of $40 \mathrm{~mm}$ the forging was solution heat treated at $980{ }^{\circ} \mathrm{C}$ for $1 \mathrm{~h}$ followed by a two step ageing operation, the first one at $760^{\circ} \mathrm{C}$ for $5 \mathrm{~h}$ and the second one at $650{ }^{\circ} \mathrm{C}$ for $1 \mathrm{~h}$.

Table I. Range of chemical composition (wt.\%) and yield strength (MPa) of the parts.

\begin{tabular}{|c|c|c|c|c|c|c|c|c|c|c|c|c|}
\hline $\mathrm{Ni}$ & $\mathrm{Cr}$ & $\mathrm{Fe}$ & Mo & $\mathrm{Nb}$ & $\mathrm{Ti}$ & $\mathrm{Al}$ & $\mathrm{Mn}$ & $\mathrm{Si}$ & $\mathrm{C}$ & $\mathrm{N}$ & B & $\begin{array}{l}\text { Yield } \\
\text { strength }\end{array}$ \\
\hline $\begin{array}{l}52.21- \\
54.02\end{array}$ & $\begin{array}{l}17.55- \\
18.39\end{array}$ & $\begin{array}{l}17.57- \\
18.52\end{array}$ & $\begin{array}{l}2.86- \\
3.06\end{array}$ & $\begin{array}{l}5.30- \\
5.44\end{array}$ & $\begin{array}{l}0.91- \\
1.08\end{array}$ & $\begin{array}{l}0.45- \\
0.61\end{array}$ & $\begin{array}{l}0.05- \\
0.10\end{array}$ & $\begin{array}{l}0.06- \\
0.11\end{array}$ & $\begin{array}{l}0.034- \\
0.038\end{array}$ & $\begin{array}{l}0.0047- \\
0.0074\end{array}$ & $\begin{array}{l}0.0027- \\
0.0050\end{array}$ & $\begin{array}{l}930- \\
1170\end{array}$ \\
\hline
\end{tabular}

All tested parts had a chemical composition and mechanical properties (Table I) well within the limits of the specification for the part.

$\underline{\text { Materials - study II }}$

Since the variation in microstructure was small in the production material, designed material with larger variations in grain size and amount of $\delta$-phase was manufactured from an ingot of Inconel 718. The chemical composition was equal in all four rings to exclude this effect (Table II).

Table II. Chemical composition (wt.\%).

\begin{tabular}{|l|l|l|l|l|l|l|l|l|l|l|l|}
\hline $\mathrm{Ni}$ & $\mathrm{Cr}$ & $\mathrm{Fe}$ & $\mathrm{Mo}$ & $\mathrm{Nb}$ & $\mathrm{Ti}$ & $\mathrm{Al}$ & $\mathrm{Mn}$ & $\mathrm{Si}$ & $\mathrm{C}$ & $\mathrm{N}$ & $\mathrm{B}$ \\
\hline 52.37 & 18.28 & Bal. & 2.90 & 5.40 & 1.00 & 0.58 & 0.07 & 0.11 & 0.035 & 0.005 & 0.004 \\
\hline
\end{tabular}

The ingot used was double melted as in study I and converted to a $203 \mathrm{~mm}$ billet. The billet was upset and punched and the forging was shaped through three ring-rolling operations. The final geometry was an outer diameter of $440 \mathrm{~mm}$, inner diameter of $330 \mathrm{~mm}$ and a height of $100 \mathrm{~mm}$.

Table III. Upset- and ring-rolling temperatures $\left({ }^{\circ} \mathrm{C}\right)$.

\begin{tabular}{|l|l|l|l|l|}
\hline Ring no. & Upset & $1^{\text {st }}$ roll & $2^{\text {nd }}$ roll & $3^{\text {rd }}$ roll \\
\hline 1 & 1093 & 1093 & 1052 & 1024 \\
\hline 2 & 1093 & 1093 & 1052 & 968 \\
\hline 3 & 996 & 996 & 982 & 982 \\
\hline 4 & 996 & 996 & 982 & 982 \\
\hline
\end{tabular}

After the forging process the rings were solution heat treated with a following standard age heat treatment.

Table IV. Heat treatment procedures.

\begin{tabular}{|l|l|l|}
\hline Ring no. & Solution heat treatment & Age heat treatment \\
\hline 1 & $996{ }^{\circ} \mathrm{C} / 1 \mathrm{~h}$ & $718^{\circ} \mathrm{C} / 8 \mathrm{~h}+621{ }^{\circ} \mathrm{C} / 8 \mathrm{~h}$ \\
\hline 2 & $968^{\circ} \mathrm{C} / 1 \mathrm{~h}$ & $718^{\circ} \mathrm{C} / 8 \mathrm{~h}+621{ }^{\circ} \mathrm{C} / 8 \mathrm{~h}$ \\
\hline 3 & $996{ }^{\circ} \mathrm{C} / 1 \mathrm{~h}$ & $718^{\circ} \mathrm{C} / 8 \mathrm{~h}+621{ }^{\circ} \mathrm{C} / 8 \mathrm{~h}$ \\
\hline 4 & $968^{\circ} \mathrm{C} / 1 \mathrm{~h}$ & $718^{\circ} \mathrm{C} / 8 \mathrm{~h}+621{ }^{\circ} \mathrm{C} / 8 \mathrm{~h}$ \\
\hline
\end{tabular}


The forging- and solution temperatures according to table III and IV respectively, were chosen to cause large differences in microstructure in the four rings. The target microstructures are presented in table 5 .

Table V. Target microstructures.

\begin{tabular}{|l|l|l|l|}
\hline Ring no. & $\begin{array}{l}\text { Unrecrystallized } \\
\text { microstructure }\end{array}$ & Grain size & Amount of $\delta$-phase \\
\hline 1 & Low & Large & Low \\
\hline 2 & High & Large & High \\
\hline 3 & Low & Small & Low \\
\hline 4 & Low & Small & High \\
\hline
\end{tabular}

Metallographic preparation

On all parts in both studies, a test ring shared with the forging was parted for quality assurance. Samples in the radial direction were acquired from the test ring and mounted into a conductive polymer. The samples were then grinded with 240, 400 and 800 grit grinding paper and finally polished with 9- and $3 \mu \mathrm{m}$ diamond paste successively. The polished samples were swab etched with Kalling's reagent [1] for a few seconds. The microstructures were analysed with light optical microscopy, scanning electron microscopy and energy dispersive X-ray spectroscopy. The volume fraction of carbides was determined by systematic manual point counting 40 fields each with 500 points, each at 500x magnification.

Machining and tool wear measurements - study I

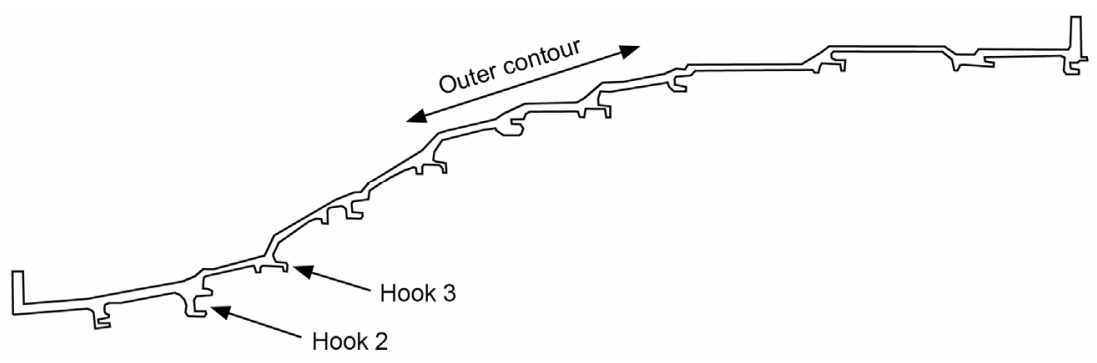

Figure 1. Sketch showing the cross section of the low pressure turbine case. The tool wear on tools from hook 2 , hook 3 and the outer contour were measured.

A sketch of the cross section of the low pressure turbine case can be seen in figure 1 . Both ceramic and carbide tools are used when machining the case. In this study, tools from 90 cases were evaluated and only cemented carbide tool inserts (figure 2a) from the machining of the outer contour and two hooks were selected. Tool wear is easier to quantify on a carbide tool than on a ceramic tool. In production, the largest change of machinability was experienced when grooving the hooks. 


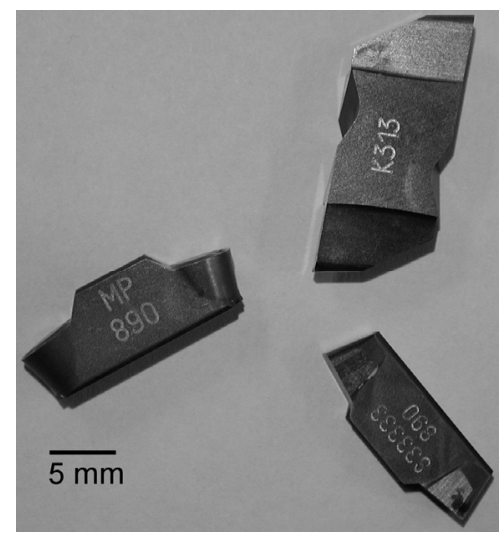

(a)

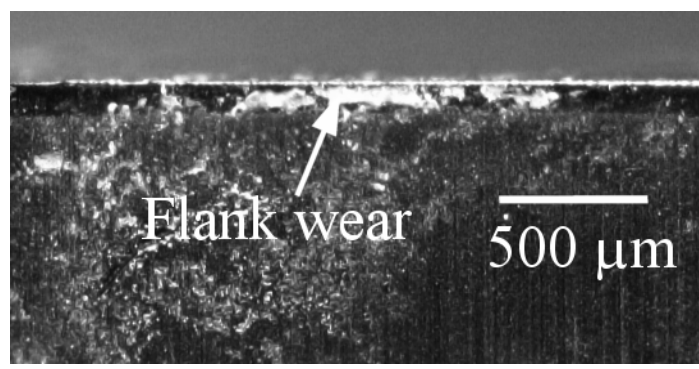

(b)

Figure 2 (a) The three cemented carbide tools studied. (b) Tool used for machining hook 3 . The flank wear is shown as the narrow worn field at the top of the tool. The height of this field is the flank wear measurement.

Production parameters such as cutting speed, feed and cutting time were held constant during the whole test series. The height of the flank wear on the tools was measured in a light microscope at $30 \mathrm{x}$ magnification (figure $2 \mathrm{~b}$ ). This flank wear was correlated to the chemical composition of the work piece recorded with X-ray spectroscopy as presented in the material certificate from the raw material supplier. In addition, data as hardness, microstructure and tensile strength from the test rings were used.

\section{$\underline{\text { Machining and tool wear measurements - study II }}$}

The machining trials were performed as turning tests in a production machine at Volvo Aero (figure 3). The tool geometry was orthogonal and the tool was of cemented carbide type.

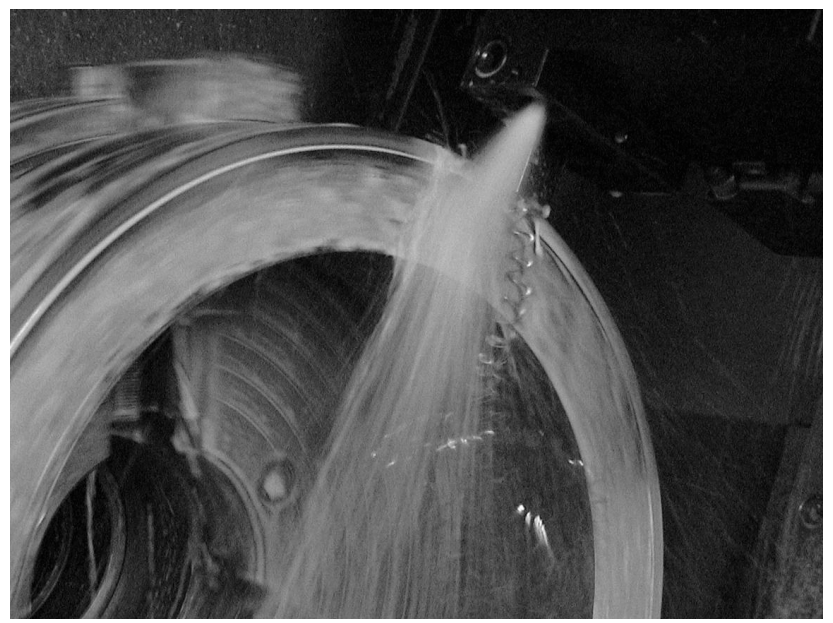

Figure 3. Machining of Inconel 718. The tool is fed from the outer radius towards the inner radius.

The rings were machined by transversal turning using three sets of machining parameters (table VI). In the first trial a tool with a nose radius of $0.8 \mathrm{~mm}$ and a depth of cut of $1 \mathrm{~mm}$ were used. During the evaluation of the tool it was found that a major part of the worn surface was out of focus in the microscope due to the large nose radius and the relatively small depth of cut. The depth of cut was therefore increased to $2 \mathrm{~mm}$ in the second trial and in the third trial the nose radius was $0.4 \mathrm{~mm}$ with the original depth of cut. 
Table VI. Machining parameters used when machining the designed forgings.

\begin{tabular}{|l|l|l|l|l|}
\hline Trial no. & $\begin{array}{l}\text { Cutting speed } \\
(\mathrm{m} / \mathrm{min})\end{array}$ & Feed $(\mathrm{mm} / \mathrm{rev})$ & $\begin{array}{l}\text { Depth of cut } \\
(\mathrm{mm})\end{array}$ & $\begin{array}{l}\text { Nose radius on } \\
\text { tool }(\mathrm{mm})\end{array}$ \\
\hline 1 & 30 & 0.2 & 1 & 0.8 \\
\hline 2 & 30 & 0.2 & 2 & 0.8 \\
\hline 3 & 30 & 0.2 & 1 & 0.4 \\
\hline
\end{tabular}

The cutting length was divided into 5 equal distances and the tool was examined after each distance by photographing. The tool wear was measured at several places as a measure of machinability (figure 4).

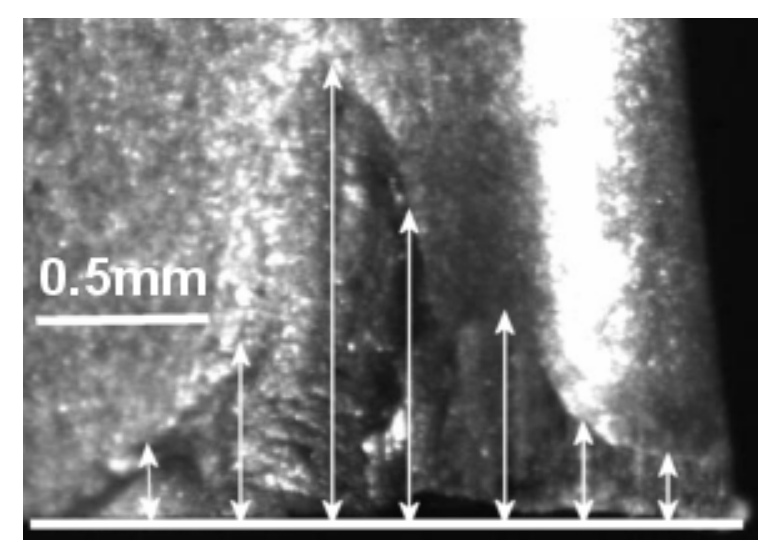

Figure 4. Tool used for machining ring 2 after the final cut. The arrows indicate how the heights of the worn area were measured.

\section{Results}

\section{$\underline{\text { Microstructures - study I }}$}

The low pressure turbine cases showed only small variations in microstructure within the material investigated. The microstructure consist of predominantly recrystallised grains with a grain size of ASTM 5-8. The main precipitates identified by colour and shape in the optical microscope are $\delta$-phase and primary carbides. Other inclusions present in the alloy, like $\gamma^{\prime}\left(\mathrm{Ni}_{3}[\mathrm{Ti}, \mathrm{Al}]\right)-$ and $\gamma^{\prime}$ ' $\left(\mathrm{Ni}_{3}[\mathrm{Nb}, \mathrm{Ta}]\right)$-precipitates would need high resolution TEM techniques for proper detection, and it was not applied here. The $\delta$-phase precipitates had a size of 0.5 to $5 \mu \mathrm{m}$ and were found both at grain boundaries and intergranularly. The volume fraction of this phase was estimated to $5-7$ vol.\%.

The primary carbides were unevenly distributed within the structure. Their amount was 0.3 to 0.4 vol.\% and thus considerably less than that of the $\delta$-phase. They had a blocky shape with a size of 3-10 $\mu \mathrm{m}$ (figure 5). EDX investigations indicated that these carbides were of two different kinds: $95 \%$ of them were $\mathrm{Nb}$-rich $\mathrm{NbC}$-carbides and the rest was Ti-rich $\mathrm{Ti}(\mathrm{C}, \mathrm{N})$-carbides. The $\mathrm{NbC}$ inclusions occur in groups or stringers, while $\mathrm{Ti}(\mathrm{C}, \mathrm{N})$ is present as isolated inclusions with occasional small groups appearing. 


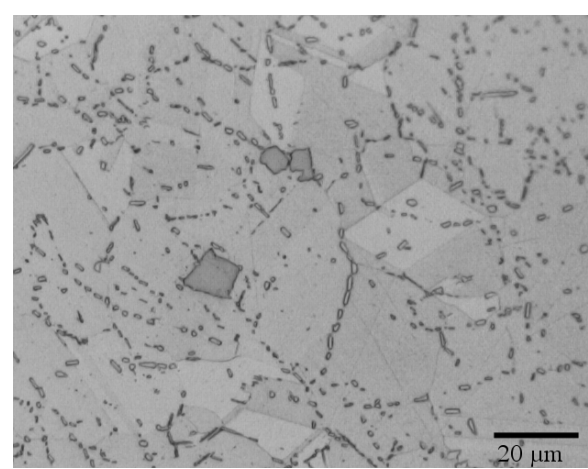

(a)

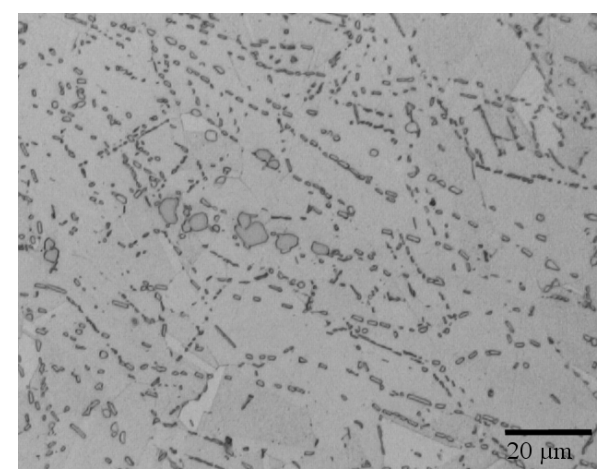

(b)

Figure 5. Optical micrograph showing primary carbides. (a) $\mathrm{Ti}(\mathrm{C}, \mathrm{N})$ and (b) stringer with $\mathrm{NbC}$.

\section{$\underline{\text { Microstructures - study II }}$}

The different forging- and solution heat treatment temperatures used produced different microstructures for the four designed rings. In particular, the grain size and the amount of $\delta$ phase differed. The carbide size and distribution was similar in each ring and normal for this type of forgings. (Table VII)

Table VII. Properties of the designed rings.

\begin{tabular}{|l|l|l|l|l|l|l|l|l|}
\hline $\begin{array}{l}\text { Ring } \\
\text { no. }\end{array}$ & $\begin{array}{l}\text { Grain } \\
\text { size } \\
(\mathrm{ASTM})\end{array}$ & $\begin{array}{l}\text { Unrecrystallized } \\
\text { structure (\%) }\end{array}$ & $\begin{array}{l}\text { Largest } \\
\text { grain } \\
(\mathrm{ASTM})\end{array}$ & $\begin{array}{l}\text { Yield } \\
\text { strength } \\
(\mathrm{MPa})\end{array}$ & $\begin{array}{l}\text { Elongation } \\
(\%)\end{array}$ & $\begin{array}{l}\text { Volume- } \\
\text { fraction } \\
\delta \text {-phase } \\
(\%)\end{array}$ & $\begin{array}{l}\text { Volume- } \\
\text { fraction } \\
\text { NbC } \\
(\%)\end{array}$ & $\begin{array}{l}\text { Volume- } \\
\text { fraction } \\
\text { Ti(C,N) } \\
(\%)\end{array}$ \\
\hline 1 & 6.5 & 0 & 5.5 & 1165 & 23 & 0.5 & 0.3 & 0.05 \\
\hline 2 & 5.0 & 100 & 3.5 & 1193 & 21 & 7.2 & 0.3 & 0.08 \\
\hline 3 & 8.5 & 0 & 7.0 & 1289 & 20 & 1.8 & 0.3 & 0.05 \\
\hline 4 & 9.5 & 0 & 8.0 & 1303 & 18 & 5.4 & 0.3 & 0.08 \\
\hline
\end{tabular}

On ring 1, the relatively large grain size was achieved through a high forging temperature yielding recrystallisation followed by grain growth. The high solution temperature led to additional grain growth and dissolution of the $\delta$-phase. The low forging temperature in the last forging step on ring 2 hindered dynamic recrystallisation of the grain structure leading to a large grained unrecrystallised microstructure. The low solution temperature gave a large volume fraction of $\delta$-phase. The forging temperature for ring 3 and 4 was chosen to yield dynamic recrystallisation and limited amount of grain growth leading to fully recrystallised fine-grained structures. Ring 3 was solution heat treated at a slightly higher temperature than ring 4 increasing the grain size and reducing the amount of $\delta$-phase.

The shape of the $\delta$-inclusions was globular except in ring 2 where it was needle shaped. The needle shaped $\delta$-phase forms at lower temperatures, but at higher temperatures the morphology becomes blockier and spherical [2]. The low forging- and solution temperatures used in ring 2 caused needle shaped $\delta$-phase, whereas the other rings were subjected to higher temperatures and had thus globular $\delta$-particles. 


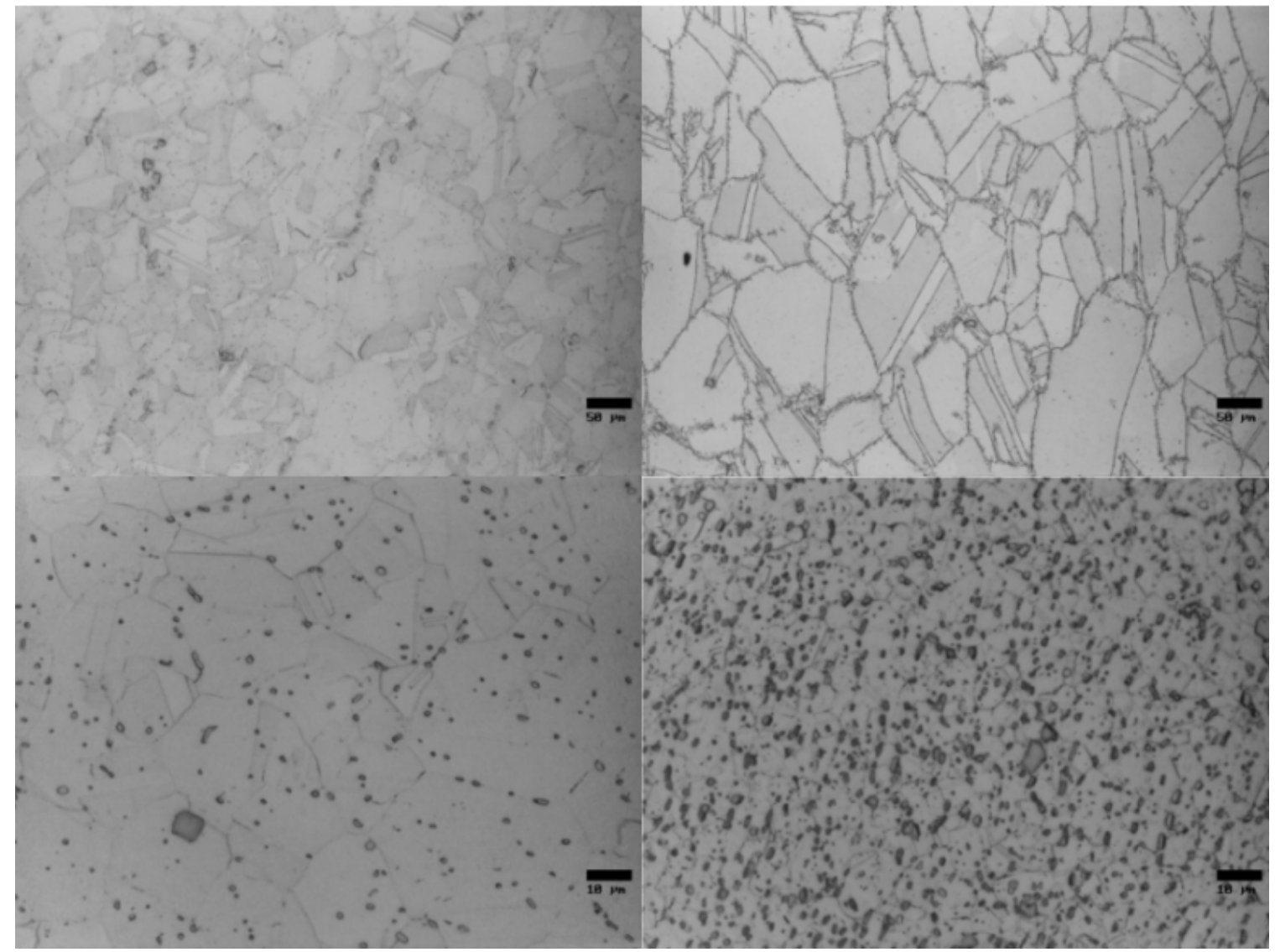

Figure 6. Optical images of the different microstructures. Upper left: ring 1. Upper right: ring 2. Lower left: ring 3. Lower right: ring 4.

\section{$\underline{\text { Tool wear - study I }}$}

The type of tool wear seen on the clearance face was flank wear (see figure 2). No crater- or notch wear could be seen on the tools used for machining the hooks, but some notching occurred on the tool used for machining the outer contour. The absence of notching when machining the hooks is caused by geometrical effects since the clearance face always cuts in undeformed material. When machining the outer contour on the other hand, the clearance face is subjected to deformation hardened material from previous cut.

The variation in flank wear during the study was small and never exceeding $0.25 \mathrm{~mm}$. In this particular operation, acceptable tool wear was set to $0.5 \mathrm{~mm}$. Larger tool wear increases the risk of tool failures.

\section{$\underline{\text { Tool wear - study II }}$}

The tool wear seen on the clearance face was flank- and notch wear. The photographs taken during the machining sequence were used for waterfall plots, which showed the development of the tool wear (figure 7). 

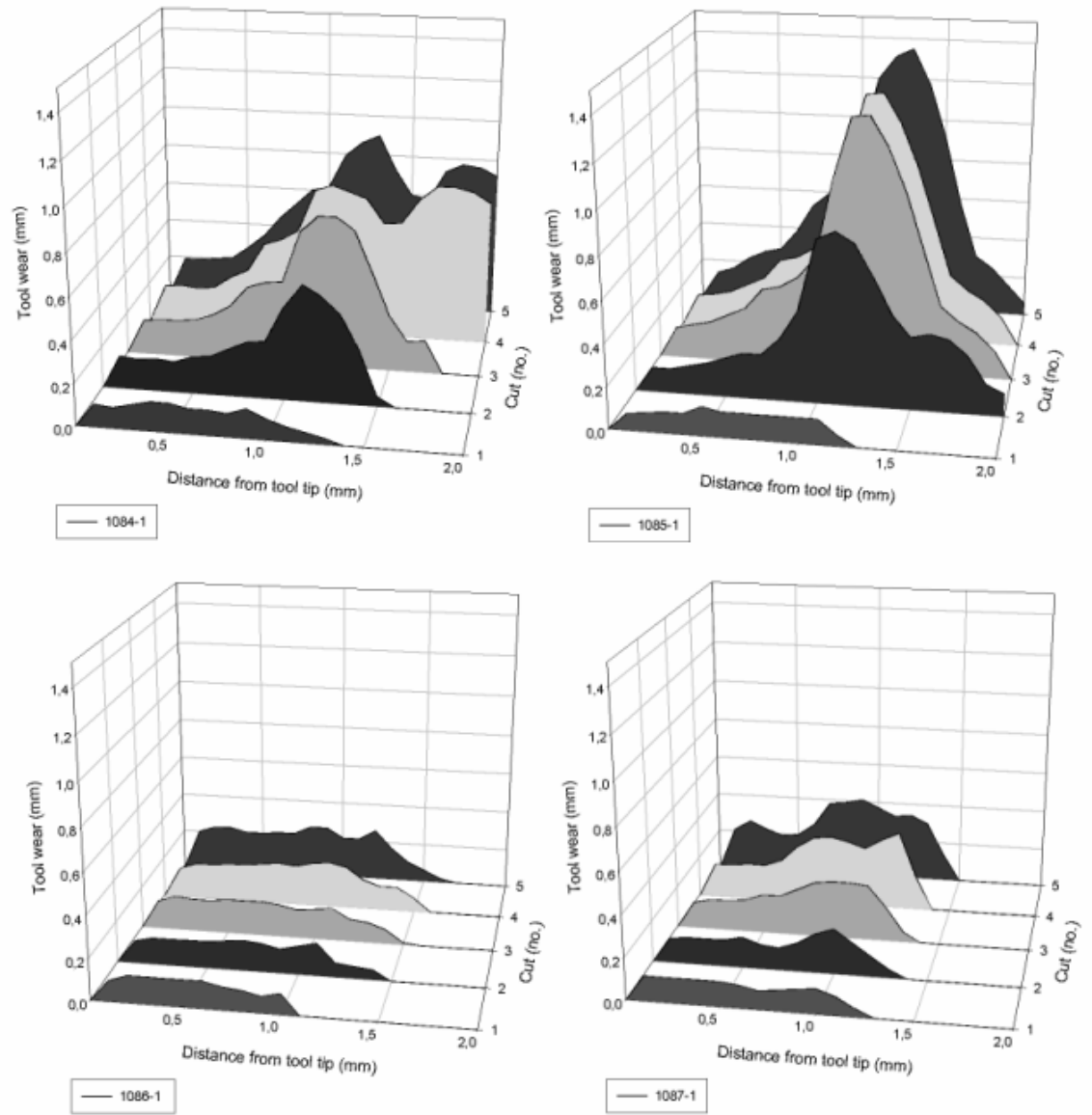

Figure 7. Tool wear development during the machining sequence. Machining parameters as in trial 1. Upper left: ring 1. Upper right: ring 2. Lower left: ring 3. Lower right: ring 4.

\section{$\underline{\text { Relations between tool wear and strength and microstructure }}$}

No influence of mechanical properties measured on test rings like yield strength, ultimate tensile strength or elongation to fracture on tool wear was seen in any of the studies.

No relation between the grain sizes in the test ring and the flank wear was found in the first study. There was a concern that the test ring was not representative for the microstructure at the cut due to that the test ring is located far from the cutting area. To confirm this, the grain size was recorded with replication technique at the location where the tool was used and it did not show any relation to tool wear. Therefore, the grain size variations in study I seem to have no influence on the machinability.

In the second study, a clear correlation between grain size and notch wear was seen where an increased grain size caused higher notch wear (figure 8). The trend was seen for all three combinations of machining parameters. Compared with the first study, the variation in grain size is larger and the effect of variations in chemical composition and production environment can be excluded. 


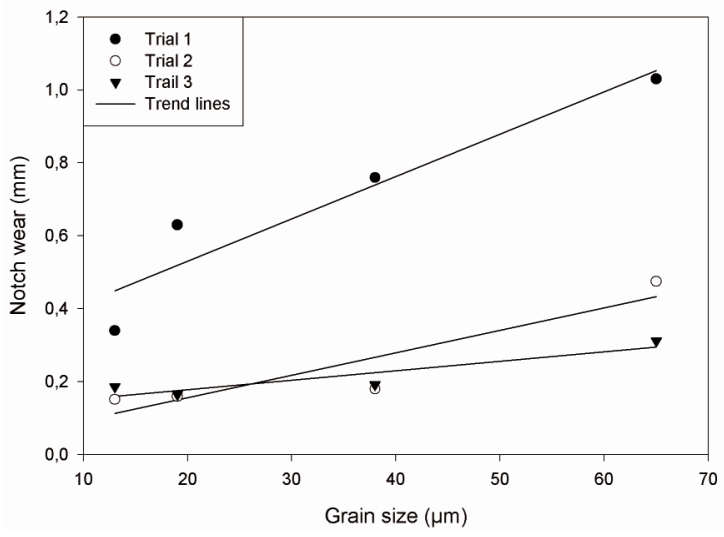

Figure 8. Grain size versus notch wear in study II.

Figure 9 indicates that the $\delta$-phase bears no simple correlation to machinability. There seems however to be a minimum in wear rate at intermediate amounts of this phase, but there is currently no explanation for this observation. Ring 3 (1.8 vol.\% $\delta$-phase) and $4(5.4 \mathrm{vol} . \% \delta$ phase) had similar microstructure apart from the difference in amount $\delta$-phase and these two rings showed no correlation between tool wear and amount $\delta$-phase.

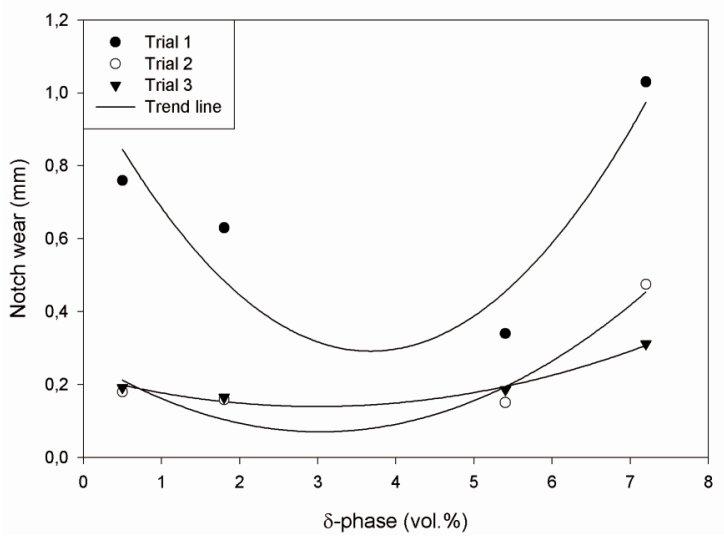

Figure 9. Volume fraction $\delta$-phase versus notch wear in study II.

$\underline{\text { Relations between tool wear and chemical composition }}$

The following figures present the tool wear as a function of the content of some chemical elements expected to influence on the machinability. The tool used for machining hook 3 (figure 1) was chosen to represent the tool wear. The other two tools showed similar results, but they are not presented here. 


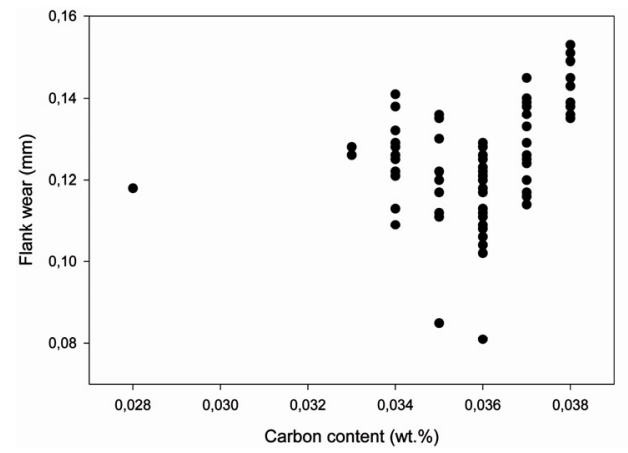

(a)

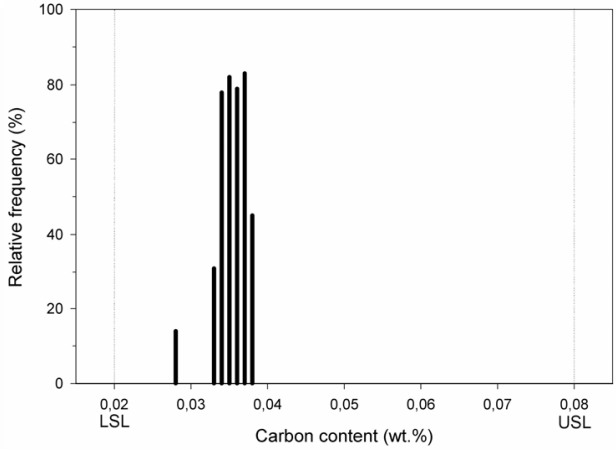

(b)

Figure 10. (a) Tool wear versus carbon content. (b) Variation in carbon content during the study. LSL represents the lower specification limit and USL represents the upper specification limit.

In figure 10 flank wear versus carbon content for different parts is presented. Even if the scatter is large, there is a weak tendency for increased wear rate with rising carbon level.

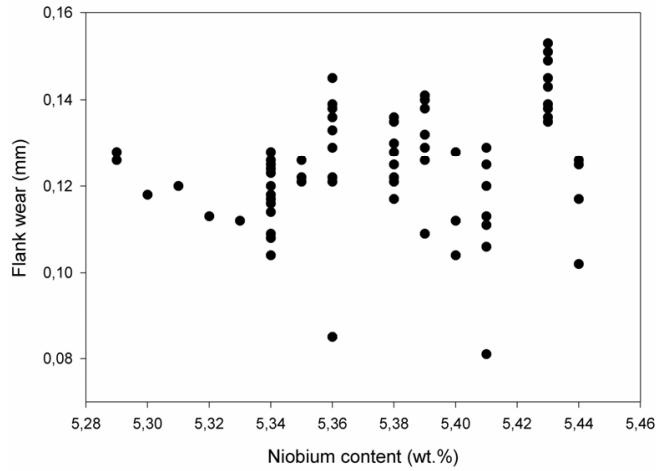

(a)

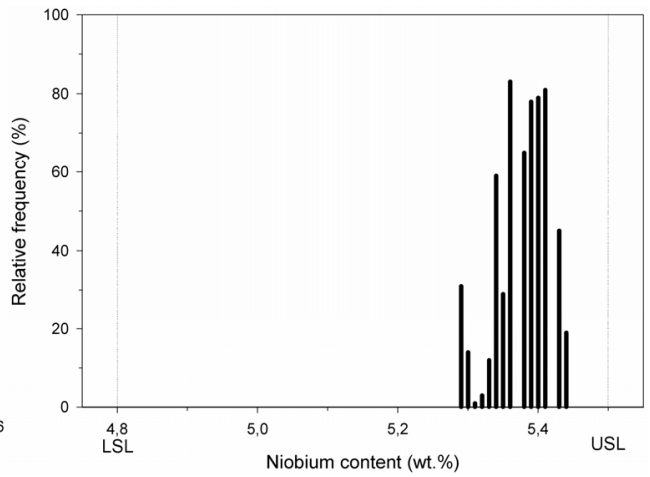

(b)

Figure 11. a) Tool wear versus niobium content. b) Variation in niobium content.

Figure 11 shows a weak correlation between tool wear and niobium content. Since the forger limits the $\mathrm{Nb}$-content to 5.3-5.5 wt.\%, the variation in this element is low.

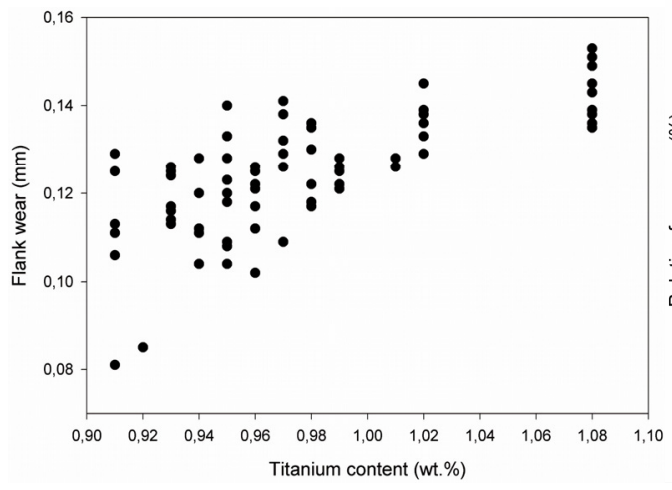

(a)

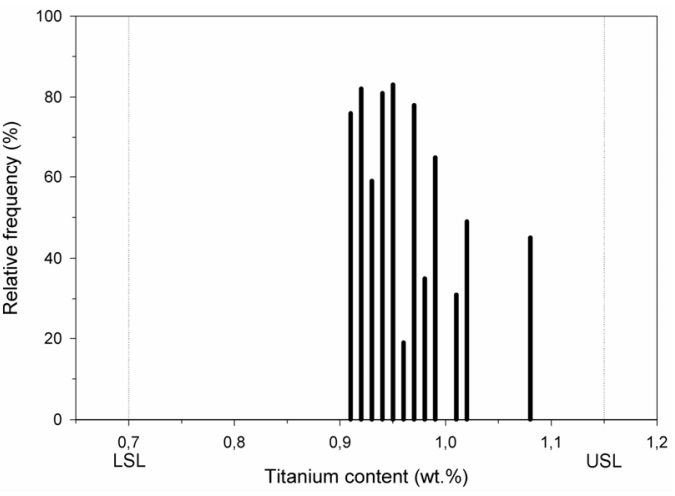

(b)

Figure 12. a) Tool wear versus titanium content. b) Variation in titanium content.

Regarding titanium, there seem to an increase of the flank wear with higher levels of this element (figure 12). The relative variation in this element is also larger than that for carbon and niobium. 


\section{Discussion}

\section{Machining}

The flank wear in the operations studied in production was low and stable. The machining parameters were chosen so that premature tool breakage was unlikely to occur, which is considered positive from a production point of view. This is particularly important in the final machining of the low pressure turbine case where scrapping a part is very costly. The operations were run to a flank wear between 0.08 and $0.15 \mathrm{~mm}$, which is considered small. This creates a buffer for variations in materials and processes which always occurs in a production environment. During the designed experiments however, it was possible to use a machining sequence producing larger tool wear. This resulted in easier analysis of tools and a clearer detection of machinability differences.

Factors influencing the machinability

A low variation in material properties is beneficial for robust manufacturing processes. During the first production study, the variation in chemical composition and microstructure of the production material has been small.

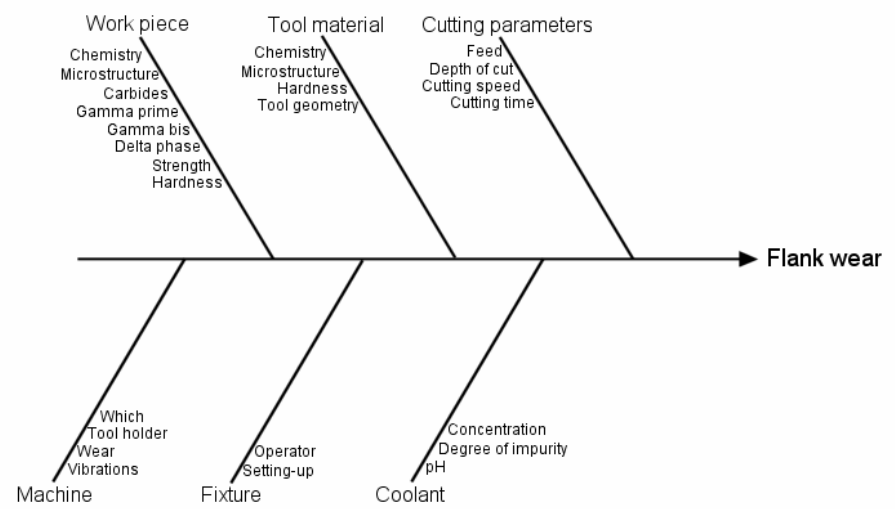

Figure 13. Fishbone diagram presenting some of the potential parameters affecting the flank wear.

The fishbone diagram in figure 13 presents some of the potential parameters affecting the flank wear. The aim of the study was to study in influence of work material and the other fluctuating parameters in the fishbone diagram are merely increasing the deviations in the study. Variations in tool material, cutting parameters, machine characteristics and coolants were kept within normal control during the studies. The scatter in the results from machining the low pressure turbine cases is yet larger than what is commonly seen in well controlled experiments. Some expected effects are hidden and not seen in the wear results. The reasons behind this behaviour can be summarized by:

- A workshop environment with variations in production parameters.

- A very consistent production material with small analysis variations making it hard to spot trends.

- A low tool wear in the production study. The potential measurement error is large compared to the actual flank wear measure. 


\section{Material behaviour during machining}

The nickel based superalloys is a material group with poor machinability. The good mechanical properties sustained at high temperatures, its ability to work harden and its hard abrasive particles cause high temperatures and high stresses in the cutting zone [3]. Literature reports different types of wear mechanisms depending on cutting parameters and type of tool material. A common view is that a built-up edge forms due to extreme strain conditions. High temperatures in combination with high local shear and compressive stresses might also cause destruction of the cutting edge [4]. The description of tool wear is complicated and the tool wear mechanisms on the flank- and rake face might be different and influence each other [5].

Focke et al. concluded that the main tool wear mechanism when machining Inconel 718 using cemented carbide tools is abrasion wear [5]. Hard particles like carbides in the work material cause abrasion on the tool. Like other studies, the tool wear measurements confirmed the hypothesis that carbide forming elements affect the machinability [6]. Titanium and niobium in Inconel 718 form primary carbides that are abrasive and bulky precipitates. TiC has a melting point at $3200{ }^{\circ} \mathrm{C}$ and a hardness of $2200 \mathrm{HV}$ [7] at room temperature. They undergo no major phase transformations up to their melting point and are therefore some of the most stable compounds existing. They are formed during solidification and are due to their properties not substantially affected by the different forging steps in the manufacturing process. As seen in figure 14, $\mathrm{TiC}$ and $\mathrm{NbC}$ are harder than $\mathrm{WC}$ in the cemented carbide tool at all temperatures presented in the figure. This means that the carbides in the work material are harder than the carbides in the tool during the cutting process.

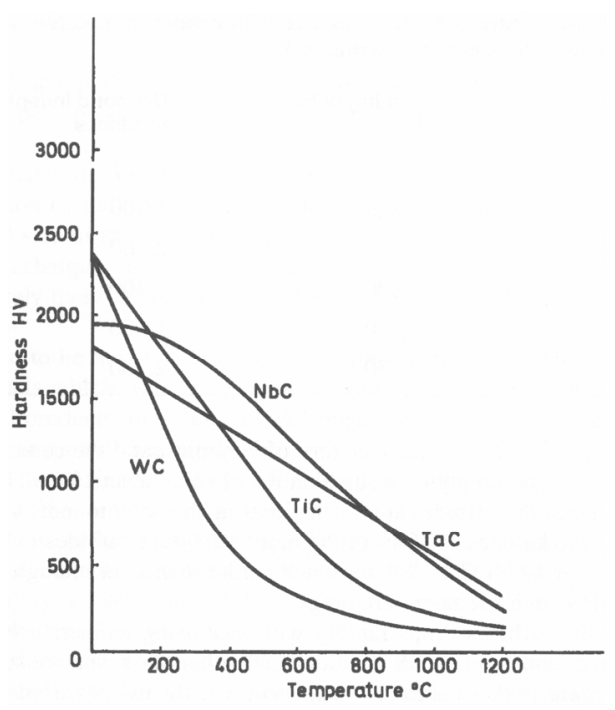

Figure 14. The variation in hot hardness of different carbides [8].

\section{Influence of alloy variations on machinability}

In this study, the correlation between carbon and niobium with flank wear is weak. This might be a result of a low variation in carbon and niobium content in the material. Former studies at Volvo Aero showed a clearer correlation for both carbon and niobium (figure 15). The material variations were larger and the machining sequence caused higher tool wear in these studies which reduced the relative measurement error when the flank wear was measured leading to more consistent results. 

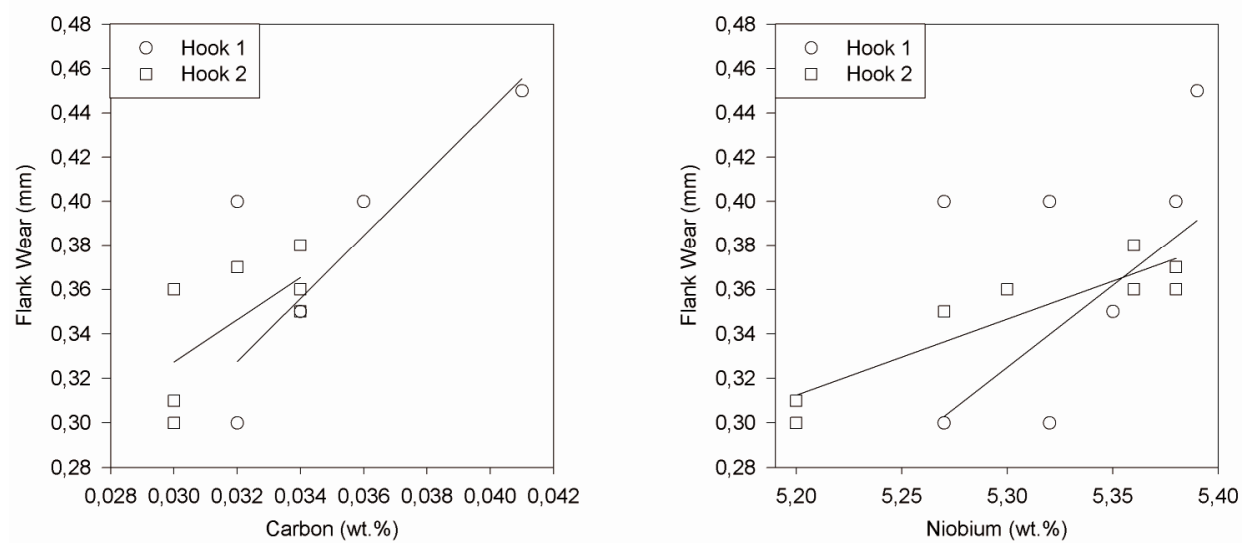

Figure 15. Flank wear versus carbon- and niobium content. The data are gathered from former studies at Volvo Aero [9].

Niobium is present in two important phases, the strengthening $\gamma$ ''-phase and the primary carbides. For titanium the situation is similar. Beside in the primary carbides, Ti is found in the $\gamma$ '-phase. The absence of correlation between flank wear and strength indicates that the primary carbides have a more important role than the $\gamma$ ''- and $\gamma^{\prime}$-phases, affecting the machinability negatively. The microstructural study shows that the volume fraction carbides are small $(\sim 0.03-$ $0.04 \%)$ and the carbides are not uniformly distributed in the alloy. The major part are $\mathrm{NbC}$ and $\mathrm{Ti}(\mathrm{C}, \mathrm{N})$ contributes only to a few percent of total carbide content. The local carbide content can however be high and if the tool is subjected to a group of carbides the result might be a momentary large tool wear. Since the primary carbides are nucleated upon nitrides [10] during the solidification process, the nitrogen content might be an important ingredient. If we assume that all primary carbides are nucleated upon nitrides, then the amount of nitrides would determine the amount of primary carbides and the amount of niobium and titanium would determine the size of the primary carbides. Since the carbides are affecting the machinability negatively the control of the carbide morphology is important. Other interstitial elements like oxygen might also affect the primary carbide precipitation process and this will be taken into account in future experiments.

\section{$\underline{\text { Influence of microstructural variations on machinability }}$}

The study on designed material showed that larger grain size leads to larger tool wear compared with rings with smaller grain size. The ring with the lowest machinability had an unrecrystallised structure and it was not resolved weather the low machinability was due to large grain size or unrecrystallised structure. Nickel based superalloys are known to work harden and machining also contributes to this type of hardening [11]. The dislocations that form during machining will be hindered by grain boundaries and the depth of deformation is therefore larger in a material with larger grain size. This might cause a more extensive tool wear for a material with large grain size. The production study showed however independence of grain size on tool wear, but this might be due to a too consistent grain size in the production material.

The role of $\delta$-phase seems to be of minor importance to the machinability. Ring 3 and 4 had similar microstructure apart from amount $\delta$-phase and when comparing the machinability for these rings it was concluded that the $\delta$-phase has low impact on tool wear. It was believed that higher amount $\delta$-phase would yield lower amount of $\gamma$ ' -phase and thus be beneficial for machinability due to lowering of strength. This was not the case and the absence of correlations to mechanical properties confirmed this. 


\section{Future work}

The study shows indications of factors influencing the machinability of Inconel 718. There are however some scatter due to variations in the production environment and low variations in the chemical composition. In order to isolate the influence of chemical composition, experiments on designed material with variations in chemical composition and constant microstructure needs to be performed. There is also an interest in machinability tests on partly recrystallised structures, where mix of large and small grains is obtained.

\section{Conclusions}

The machinability of forged Inconel 718 was studied. The main conclusions of the study are:

- Niobium, carbon and titanium are important elements affecting the machinability. These elements are present in the primary carbides that are decreasing the machinability by causing abrasive wear.

- Larger grain size causes a decrease in machinability due to larger depth of deformation.

- In fully heat treated Inconel 718, the strength is of minor importance to the machinability in the range tested.

\section{Acknowledgements}

Financial support was given by the Graduate school in Materials Science at Chalmers University of Technology. Carlton Forge Works and Carpenter are greatly acknowledged for providing material and knowledge in production processes. Co-operation with Dr. Göran Sjöberg, Mr. Anders Wretland and Mr. Frank Skystedt at Volvo Aero Corporation and Dr. Peter Sotkovszki at Chalmers University of Technology are acknowledged.

\section{References}

1. Kathleen Mills et al., eds., Metals handbook, vol. 9 (Metals Park, OH: American society for metals, 1985), 308 .

2. Matthew J. Donachie and Stephen J. Donachie, Superalloys: a technical guide, (Materials Park, OH: ASM International, 2002), 105-106.

3. I.A. Choudhury, M.A. El-Baradie, "Machinability of nickel-base super alloys: a general review", Journal of Materials Processing Technology, 77 (1998), 278-284

4. Edward M. Trent and Paul K. Wright, Metal Cutting, (Woburn, MA: Butterworth Heinemann, 2000), 301

5. A.E. Focke, F.E. Westermann, J. Kemphaus, W.T. Shih, M. Hoch, "Wear of superhard materials when cutting superalloys", Wear, 46 (1978), 65-79

6. J.J. Schirra, D.V. Viens, "Metallurgical factors influencing the machinability of Inconel 718", Superalloys 718, 625, 706 and various derivates. ed. E.A. Loria. (Warrendale, PA: The Minerals, Metals \& Materials Society, 1994), 827-838 
7. Edward M. Trent and Paul K. Wright, Metal Cutting, (Woburn, MA: Butterworth Heinemann, 2000), 177

8. Edward M. Trent and Paul K. Wright, Metal Cutting, (Woburn, MA: Butterworth Heinemann, 2000), 178

9. Viktor Recina and Frank Skystedt, (Report 9653-752, Volvo Aero Corporation, 2000).

10. A. Mitchell, A.J. Schmalz, C. Schvezov, S.L. Cockcroft, "The precipitation of primary carbides in alloy 718", Superalloys 718, 625, 706 and various derivates. ed. E.A. Loria. (Warrendale, PA: The Minerals, Metals \& Materials Society, 1994), 65-78

11. Matthew J. Donachie and Stephen J. Donachie, Superalloys: a technical guide, (Materials Park, OH: ASM International, 2002), 190. 